\title{
Early observations relating to the implementation of the Marine and Coastal Access Act 2009 in Welsh coastal waters
}

\author{
Dr Rhoda C Ballinger, School of Earth and Ocean Sciences, Cardiff University, \\ BallingerRC@cardiff.ac.uk \\ Dr Simon Jones, Faculty of Health, Sport and Sciences, University of Glamorgan \\ sdjones@glam.ac.uk
}

\begin{abstract}
Following the enactment of the Marine and Coastal Access Bill in November 2009, the Welsh Assembly Government (WAG) acquired the responsibility for the Act's implementation in Wales' coastal zone. Responsibilities extend to devising and implementing a system of marine spatial planning as well as contributing towards the establishment of an ecologically coherent UK network of marine protected areas (MPAs) in response to various international including European commitments, most notably the OSPAR Commission's Recommendation 2003.3 for a North East Atlantic MPA network (OSPAR, 2006).
\end{abstract}

With already over half of Welsh coastal waters designated as marine sites within the Natura 2000 network, WAG has initiated efforts to establish a number of Highly Protected Marine Conservation Zones (HPMCZs) by 2011. It is intended that all potentially damaging activities and disturbance will be excluded from such zones, including extraction activity, thus affording ecosystem rather than simply ecological protection to these areas. To facilitate site selection and stakeholder engagement, WAG has established a process and created a number of pan-Wales forums. These include a high level Steering Group of government and government agency representatives, a Stakeholder Advisory Group with wide geographical and sectoral membership (largely based on the pre-existing Wales Coastal and Maritime Partnership), and a Technical Advisory Group - to provide technical support and advice to the aforementioned groups as well as to collect and collate relevant data to support the selection of the zones and to use this data to develop site proposals.

With a legal duty to sustainable development and a commitment under the marine legislation for socio-economic needs to inform the definition of marine conservation zones, WAG is attempting to integrate socio-economic factors into the site selection process as well as facilitating better marine stewardship and conflict minimisation. This paper outlines the context, rationale and key characteristics of the Welsh approach to HPMCZ selection, focusing on the process for the identification of socioeconomic criteria. As such, it provides a preliminary assessment of the extent to which the various forums, mentioned above, have been able to influence the process and associated outcomes. 
Finally, the paper offers a critical review of WAG's approach to the designation of HPMCZ within the context of its responsibilities for marine spatial planning. It is suggested that the process for designating these zones will influence the development of any wider marine spatial planning framework and process. Given concerns of both academics (for example, Peel and Lloyd, 2004; Watson, 2008) and policy makers (note: Marine Spatial Planning Pilot Consortium, 2005; UNESCO, 2006) regarding the challenges associated with the development of effective marine planning processes and the potential tensions between marine protected area designation and wider marine planning, it is anticipated that these early observations from Wales will be highly relevant to other European coastal areas.

\section{References}

Marine Spatial Planning Pilot (MSPP) Consortium (2005) Options for developing, implanting and managing marine spatial planning (MSP) in UK coastal and offshore water. Marine spatial planning literature review (2005) and final report commissioned by DEFRA, London.

OSPARCOM (2006) General Report to the North Sea Ministers on the Follow-Up to the 2002 Bergen Declaration, London.

Peel, D. and Lloyd, M.G. (2004) The social reconstruction of the marine environment: towards marine spatial planning, Town Planning Review, 7593), 359 - 378

UNESCO (2006) Conclusions and next steps from the International Workshop on Marine Spatial Planning, Summary, UNESCO, Paris, November, 2006, 4pp..

Watson, N. (2008) Prospects for marine spatial planning: a social science response. Paper presented at Seminar 2 within the ESRC/NERC Trans-disciplinary Seminar Series' New approaches to managing ecosystem services in the marine environment.' 